Check for updates

Cite this: RSC Adv., 2018, 8, 14280

\title{
Computer-aided design of magnetic molecularly imprinted polymer nanoparticles for solid-phase extraction and determination of levetiracetam in human plasma $\dagger$
}

\author{
Olivia A. Attallah, (DD a Medhat A. Al-Ghobashy, ${ }^{\text {bc }}$ Ahmed Taha Ayoub, ${ }^{a}$ \\ Jack Adam Tuszynski ${ }^{d}$ and Marianne Nebsen ${ }^{\star b}$
}

Analytical methods should be accurate and specific to measure plasma drug concentration. Nevertheless, current sample preparation techniques suffer from limitations, including matrix interference and intensive sample preparation. In this study, a novel technique was proposed for the synthesis of a molecularly imprinted polymer (MIP) on magnetic $\mathrm{Fe}_{3} \mathrm{O}_{4}$ nanoparticles (NPs) with uniform core-shell structure. The $\mathrm{Fe}_{3} \mathrm{O}_{4} @ \mathrm{M}$ IPs NPs were then applied to separate and enrich an antiepileptic drug, levetiracetam, from human plasma. A computational approach was developed to screen the functional monomers and polymerization solvents to provide a suitable design for the synthesized MIP. Different analysis techniques and re-binding experiments were performed to characterize the $\mathrm{Fe}_{3} \mathrm{O}_{4}$ @MIP NPs, as well as to identify optimal conditions for the extraction process. Adsorption isotherms were best fitted to the Langmuir model and adsorption kinetics were modeled with pseudo-second-order kinetics. The $\mathrm{Fe}_{3} \mathrm{O}_{4} @$ MIP NPs showed reasonable adsorption capacity and improved imprinting efficiency. A validated colorimetric assay was introduced as a comparable method to a validated HPLC assay for the quantitation of levetiracetam in plasma in the range of $10-80 \mu \mathrm{g} \mathrm{mL}^{-1}$ after extraction. The results from the HPLC and colorimetric assays showed good precision (between $1.08 \%$ and $9.87 \%$ ) and recoveries (between 94\% and 106\%) using the $\mathrm{Fe}_{3} \mathrm{O}_{4} @ \mathrm{OMIP}$ NPs. The limit of detection and limit of quantification were estimated to be $2.58 \mu \mathrm{g} \mathrm{mL}^{-1}$ and $7.81 \mu \mathrm{g} \mathrm{mL}^{-1}$, respectively for HPLC assay and $2.32 \mu \mathrm{g} \mathrm{mL}^{-1} \mathrm{and}$ $7.02 \mu \mathrm{g} \mathrm{mL}{ }^{-1}$, respectively for colorimetric assay. It is believed that synthesized $\mathrm{Fe}_{3} \mathrm{O}_{4} @ \mathrm{aMIP}$ NPs as a sample clean-up technique combined with the proposed assays can be used for determination of levetiracetam in plasma.

Received 18th March 2018 Accepted 12th April 2018

DOI: $10.1039 / c 8 r a 02379 d$

rsc.li/rsc-advances

\section{Introduction}

Complex matrices as biological fluids constituting blood, plasma or urine contain a number of endogenous components, which if not removed may interfere and adversely affect the separation and identification of analyte(s) of interest. ${ }^{\mathbf{1}, 2}$ Such challenges made sample preparation one of the most important and crucial steps in the analytical process. ${ }^{3}$ However, one drawback of sample preparation steps is that they consume around two-thirds of the total analysis time and are considered the major source of error in the overall analytical process. ${ }^{2}$

aPharmaceutical Chemistry Department, Heliopolis University, Cairo-Belbeis Desert Rd, El-Nahda, El-Salam, Cairo Governorate 11777, Egypt

${ }^{b}$ Analytical Chemistry Department, Faculty of Pharmacy, Cairo University, Cairo 11562, Egypt. E-mail: marianne.morcos@pharma.cu.edu.eg

${ }^{c}$ Bioanalysis Research Group, School of Pharmacy, Newgiza University, Egypt ${ }^{d}$ Department of Physics, University of Alberta, Edmonton, AB T6G 2E1, Canada

$\uparrow$ Electronic supplementary information (ESI) available. See DOI: 10.1039/c8ra02379d
Extraction techniques that are routinely used in sample preparation are solid-phase extraction (SPE) and liquid-liquid extraction (LLE). ${ }^{3}$ Currently, the most appropriate method for extraction of drugs in biological fluids is SPE due to its adaptability and simplicity while LLE suffers from high consumption of labor and solvents. ${ }^{2,4}$ Nevertheless, both extraction techniques lack specific adsorption ability. ${ }^{5}$

A molecularly imprinted polymer (MIP) is a synthetic polymer that reshapes its surface according to the molecular structure of the target molecule. The application of MIPs as sorbents in SPE is quite effective and appealing because they offer higher selectivity, reduce the influence of the matrix components and provide high sample enrichment factors., ${ }^{\mathbf{2}, \mathbf{7}}$ However, MIP as adsorbents suffers from some drawbacks as the heterogeneous distribution of binding sites, low binding capacity, and slow binding kinetic. ${ }^{\mathbf{8} 9}$ Thus the development of molecular imprinting nano techniques with magnetic properties will provide a potential solution to overcome such drawbacks. ${ }^{9}$ 
Magnetic molecularly imprinted polymer nanoparticles (MMIP NPs) synthesis is a new technique achieved via encapsulating an inorganic magnetic particle with molecularly imprinted polymers. When the MMIP NPs bind the target analyte they can be easily separated from the matrix media by an external magnetic field without additional filtration or centrifugation. $^{\mathbf{8}, 10}$ In addition, MMIP NPs are expected to improve the binding capacity and fasten binding kinetics over normal imprinting materials. ${ }^{8}$ Based on such assumptions many studies nowadays adopted the idea of incorporating magnetic nanoparticles with molecularly imprinted polymers for extraction of drugs from different media. ${ }^{5,11-18}$

Levetiracetam (Fig. 1) (LEV) is an antiepileptic approved therapy for focal epilepsy and myoclonic and tonic-clonic seizures. ${ }^{19} \mathrm{LEV}$ is also licensed for use as adjunctive therapy to other first line anti-epileptic drugs in adult patients with partial onset seizures and is often prescribed with antipsychotic drugs. ${ }^{20,21}$ LEV has a concentration ranging between 12 to $46 \mathrm{mg}$ $\mathrm{mL}^{-1}$ in plasma. ${ }^{22,23}$ and its plasma protein binding is low (10\%). LEV also undergoes insignificant hepatic metabolism to inactive metabolites and about $91 \%$ of the dose is excreted through renal route. ${ }^{24}$ Nevertheless, it is recommended to monitor the plasma concentrations of LEV to optimize its therapeutic effect, especially in patients with renal impairment, and in children, where the half-life of the drug is shortened and in the elderly where the half-life is extended..$^{25,26}$ There are only a few papers published reporting therapeutic drug monitoring methods of LEV employing different chromatographic techniques including HPLC with UV-detection, ${ }^{27,28}$ and GC with NPD-detection. ${ }^{27,29}$ Chromatographic techniques are commonly sensitive and selective, yet, they require toxic solvents, expensive equipment, in addition to complex sample pretreatments. Thus, spectroscopic techniques are more convenient for routine

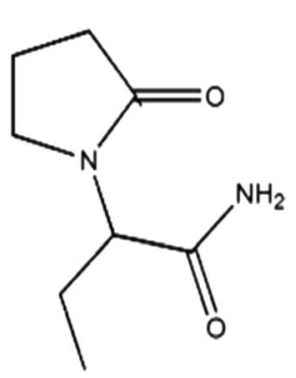

Levetiracetam (LEV)

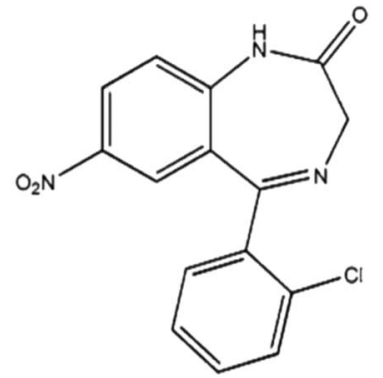

Clonazepam (CLO)
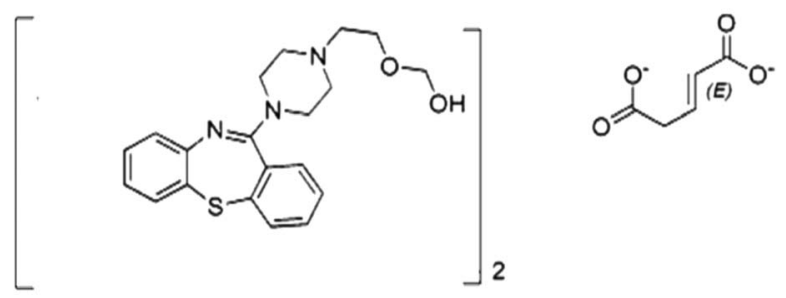

Quetiapine fumarate (QF)

Fig. 1 Chemical structure of levetiracetam and its co-administered drugs. laboratory analysis. Nevertheless, such spectroscopic techniques if not combined with sample pretreatment steps, may suffer from the influence of interfering biological samples components. Thus, sample preparation is considered a very crucial step. ${ }^{30}$

In this work, we present a novel method to prepare a molecularly imprinted polymer layer on magnetic $\mathrm{Fe}_{3} \mathrm{O}_{4} \mathrm{NPs}$ to separate and enrich LEV from human plasma. To improve the properties of the synthesized MIP, a computer-aided study has been proposed. The morphology, chemical characteristics and adsorption properties of the $\mathrm{Fe}_{3} \mathrm{O}_{4} @$ @MIPs NPs were evaluated using different characterization techniques. LEV concentration in plasma was quantified via two novel validated assays; HPLC-UV and colorimetry.

\section{Experimental}

\subsection{Materials}

Levetiracetam, quetiapine fumarate, and clonazepam powders were kindly provided by Eva Pharmaceuticals, Chemi pharm, and Amoun pharmaceutical company respectively (Cairo, Egypt). Ferric chloride anhydrous $\left(\mathrm{FeCl}_{3}\right)$, ferrous sulfate heptahydrate $\left(\mathrm{FeSO}_{4} \cdot 7 \mathrm{H}_{2} \mathrm{O}\right)$, ammonia solution $(25 \%, \mathrm{w} / \mathrm{w})$ and tetraethoxysilane (TEOS) were purchased from Fisher Scientific (USA). Oleic acid was purchased from central drug house (India). Methacryloxypropyl trimethoxysilane (MPS) was obtained from Sigma Aldrich (China). Methacrylic acid (MAA), ethylene glycol dimethacrylate (EGDMA) were purchased from Aldrich (Germany) and azobisisobutyronitrile (AIBN) from Levochem (USA), human blank plasma was obtained from the Holding Company for Biological Products and Vaccines (VACSERA), Egypt. HPLC grade acetonitrile, acetone, and methanol were purchased from Fisher Scientific (UK). Potassium dihydrogen phosphate was purchased from Sigma Aldrich (Germany). All other chemicals and reagents used were of analytical grade or higher.

\subsection{Instrumentation}

The morphologies and dimensions of the synthesized nanoparticles were characterized using scanning electron microscopy (SEM) in a Zeiss instrument (Germany) and the transmission electron microscopy (TEM) on Tecani G20, FEI transmission electron microscope (USA). The structure of the synthesized nanoparticles was characterized by X-ray diffractometer (a Rigaku model Geigerflex apparatus). Fourier transform infrared (FT-IR) spectra ( $\mathrm{KBr}$ pellets) were performed on a Perkin Elmer Spectrum GX spectrophotometer. Magnetic properties were analyzed using a vibrating sample magnetometer (Princeton EG and G Applied Research VSM, Model 155). The concentrations of levetiracetam in the solutions were determined by a Single beam UV-Vis model AE-S90-MD form A \& E Lab (UK). High performance liquid chromatography (HPLC) was performed on an Agilent liquid chromatograph system model 1100 (Agilent Technologies, USA). The variable wavelength UV-Vis detector was operated at $\lambda_{\max }$ for investigated drug determinations. 


\subsection{Computational approach}

Computational chemistry tools were applied in order to estimate the affinities of different monomers to the template drug levetiracetam in different solvents. This strategy saves a lot of time and effort since one does not have to select monomers and solvents based on trial and error in the laboratory. In our computational study, the monomers tried were acrylamide (AAM), methacrylic acid (MAA), methyl methacrylate (MMA), acrylonitrile (AN) and divinylbenzene (DVB). The solvents tried were chloroform, methanol, acetonitrile, dimethyl sulfoxide (DMSO), and acetone. Firstly, a stochastic conformational search of the template-monomer complex was performed on Molecular Operating Environment (MOE) ${ }^{31}$ using the default settings. The MMFF94x force field was used with a distancedependent dielectric model. In most of the cases, two possible $1: 1$ complexes between template and monomer were obtained with a slight difference in energy, and only one reasonable $1: 2$ complex was obtained. These three complexes, involving 5 different monomers and in 5 different solvents were investigated using $a b$ initio quantum mechanics. All the $a b$ initio calculations were done using Gaussian 09 (ref. 32) on Pharmamatrix Cluster, University of Alberta. Geometry optimization of the template, monomer, and template-monomer complex was done employing the Hartree-Fock level of theory with the 6$31 \mathrm{G}(\mathrm{d})$ basis set. Frequency analysis was done to ensure the absence of imaginary frequencies at the optimized structures. The Polarizable Continuum Model (PCM) ${ }^{33}$ was employed to account for the different solvent effects. The interaction energy between the template and the monomer(s) was calculated using the following equation:

$$
\Delta E=E_{\text {template-monomer complex }}-E_{\text {template }}-\Sigma E_{\text {monomers }}
$$

Images were created using VMD version 1.9.2. ${ }^{34}$ It is worth mentioning that counterpoise correction (CP) for the basis set superposition error (BSSE) was not employed. The utility of applying this correction is questionable especially if one only wants to rank the relative binding energies with no significance for absolute binding energies. It was shown that correction for BSSE only affects the absolute values of the binding energies without affecting the relative ranking of different monomers. ${ }^{35,36}$

\subsection{Preparation of magnetic molecularly imprinted polymer nanoparticles (MMIP NPs) for LEV extraction}

2.4.1. Synthesis of $\mathrm{Fe}_{3} \mathrm{O}_{4}$ @oleic acid NPs. The synthesis of the magnetite $\left(\mathrm{Fe}_{3} \mathrm{O}_{4}\right)$ NPs was done via a co-precipitation technique. $100 \mathrm{~mL}$ of $0.4 \mathrm{M} \mathrm{FeCl}_{3}$ aqueous solution were mixed with $100 \mathrm{~mL}$ of $0.2 \mathrm{M} \mathrm{FeSO}_{4}$ aqueous solution. Then, $100 \mathrm{~mL}$ of $3.0 \mathrm{M} \mathrm{NaOH}$ aqueous solution was added dropwise under continuous stirring. Finally, $2.0 \mathrm{~mL}$ of oleic acid was added and the reaction mixture was heated to $80{ }^{\circ} \mathrm{C}$ for $1 \mathrm{~h}$. The black precipitate product was washed several times with ultrapure water and methanol to remove excess oleic acid from the solution and the precipitate was dried at $70{ }^{\circ} \mathrm{C}$ for $5 \mathrm{~h} .{ }^{37}$
2.4.2. Synthesis of the $\mathrm{Fe}_{3} \mathrm{O}_{4} @$ @oleic acid@SiO $\mathrm{SPs}_{2}$ NPs $300 \mathrm{mg}$ of $\mathrm{Fe}_{3} \mathrm{O}_{4}$ @oleic acid NPs were dispersed in $40 \mathrm{~mL}$ ethanol and $4.0 \mathrm{~mL}$ of purified water via sonication for $15 \mathrm{~min}$, followed by the addition of $2.0 \mathrm{~mL}$ ammonium hydroxide and $2.0 \mathrm{~mL}$ TEOS consecutively. The mixture was reacted for $18 \mathrm{~h}$ at room temperature under continuous stirring. The obtained product was collected by an external magnetic field, washed with methanol several times, and dried at $70{ }^{\circ} \mathrm{C}$ for $5 \mathrm{~h} .{ }^{14}$

2.4.3. Synthesis of vinyl-modified $\mathrm{Fe}_{3} \mathrm{O}_{4}$ NPs. $250 \mathrm{mg}$ of $\mathrm{Fe}_{3} \mathrm{O}_{4} @ \mathrm{SiO}_{2}$ NPs was dispersed in $50 \mathrm{~mL}$ methanol by sonication for $10 \mathrm{~min}$ and $3.0 \mathrm{~mL}$ of MPS were added dropwise while stirring. The mixture was then reacted for $24 \mathrm{~h}$ at the room temperature under continuous stirring. The obtained product was collected by an external magnetic field and washed with methanol and dried in vacuum. ${ }^{13}$

2.4.4. Synthesis of the core-shell $\mathrm{Fe}_{3} \mathrm{O}_{4} @ \mathrm{MIP}$ and $\mathrm{Fe}_{3}$ $\mathbf{O}_{4} @ N I P$ NPs. The $\mathrm{Fe}_{3} \mathrm{O}_{4} @$ MIP NPs were prepared using a noncovalent imprinting technique. The template molecule LEV $(0.55 \mathrm{mmol})$ was mixed with the selected functional monomer MAA $(2.2 \mathrm{mmol})$ in $30 \mathrm{~mL}$ chloroform as selected polymerization solvent, and the mixture was stirred for $12 \mathrm{~h}$ to form template-monomer complex. Vinyl modified $\mathrm{Fe}_{3} \mathrm{O}_{4}(200 \mathrm{mg})$, EGDMA (11 mmol) and AIBN (50 mg) were then added to the above solution. To remove dissolved oxygen, the solution was stirred under vacuum for $5 \mathrm{~min}$. The mixture was then heated to reflux, $60{ }^{\circ} \mathrm{C}$ for $24 \mathrm{~h}$. The $\mathrm{Fe}_{3} \mathrm{O}_{4} @$ MIP NPs were rinsed with ethanol, acetonitrile and diethyl ether until the supernatant was clear. The template molecule LEV was extracted from the polymer with 90/10 (v/v) MeOH/acetic acid mixture in a Soxhlet extraction system during $72 \mathrm{~h}$. Finally, the obtained product was dried in the air. Non-imprinted $\mathrm{Fe}_{3} \mathrm{O}_{4} @$ NIP NPs were prepared following the same procedure in the absence of the template LEV.

\subsection{Analysis techniques}

2.5.1. Colorimetric method for binding experiments. Stock solution $\left(0.1 \mathrm{mg} \mathrm{mL} \mathrm{mL}^{-1}\right)$ of LEV was prepared in methanol. Aliquots of the stock solution were transferred into $25 \mathrm{~mL}$ volumetric flasks. $0.5 \mathrm{~mL}$ of $(1 \%(\mathrm{w} / \mathrm{v}))$ ferric chloride; (freshly prepared by dissolving $500 \mathrm{mg}$ of ferric chloride in $5 \mathrm{~mL}$ concentrated $\mathrm{HCl}$ and complete volume to $50 \mathrm{~mL}$ with distilled water), and $0.5 \mathrm{~mL}$ of $(0.2 \%(\mathrm{w} / \mathrm{v}))$ potassium ferricyanide; (prepared by dissolving $100 \mathrm{mg}$ of Potassium ferricyanide in $50 \mathrm{~mL}$ distilled water) were added and final volume was made up to the mark with methanol. A Prussian blue colored product was formed immediately at room temperature. Absorbance of the samples was measured at $775 \mathrm{~nm}$ against the reagent blank prepared in the same manner. Calibration curve for LEV was obtained by plotting absorbance at the $\lambda_{\max }=775 \mathrm{~nm}$ against concentration. Various assay validation parameters were then calculated according to ICH guidelines. ${ }^{38-40}$

2.5.2. Spectrophotometric method for binding experiments. Standard solutions $\left(0.1 \mathrm{mg} \mathrm{mL}^{-1}\right)$ of quetiapine fumarate (QF) and clonazepam (CLO) were prepared in methanol separately. Solutions were scanned in the range of 200-400 nm and the wavelength of maximum absorption for each drug was 
determined. Accurate volumes of quetiapine fumarate and clonazepam stock solutions $(0.3,0.6,1.2,1.8,2.4$ and $3.0 \mathrm{~mL})$ were transferred into $10 \mathrm{~mL}$ volumetric flasks separately and diluted to volume with methanol. Calibration curves for the investigated drugs were obtained by plotting absorbance at the $\lambda_{\max }$ of each drug; $245 \mathrm{~nm}$ and $250 \mathrm{~nm}$ for QF and CLO respectively, against concentration. Various assay validation parameters were then calculated according to $\mathrm{ICH}$ guidelines. $^{\mathbf{3 8 - 4 0}}$

\subsection{Binding experiments for optimization of molecular imprinting magnetic solid phase extraction (MI-MSPE) procedure}

Preliminary studies were carried out to determine best solvent for extraction of the target drug LEV and the contact time required to reach equilibrium. $150 \mathrm{mg}$ of $\mathrm{Fe}_{3} \mathrm{O}_{4} @$ @IP NPs were added into $30 \mathrm{~mL}$ of LEV solution of initial concentration $\left(100 \mathrm{mg} \mathrm{L}^{-1}\right)$ at neutral $\mathrm{pH}$ and shaken at $25{ }^{\circ} \mathrm{C}$. After defined time intervals, samples were removed and the absorbance of LEV left in the supernatant solutions after magnetic separation were determined using the validated colorimetric assay.

The influence of $\mathrm{pH}$ on the extraction of LEV was investigated using $100 \mathrm{mg} \mathrm{L}^{-1}$ of LEV solution over $\mathrm{pH}$ range of 3.011.0 adjusted using $0.1 \mathrm{M} \mathrm{HCl}$ and $0.1 \mathrm{M} \mathrm{NaOH}$. To each of the pH-adjusted LEV solution, 25 mg of $\mathrm{Fe}_{3} \mathrm{O}_{4} @$ @IP NPs was added and shaken for $30 \mathrm{~min}$ at $25^{\circ} \mathrm{C}$.

To study the effect of adsorbent concentration 25-200 $\mathrm{mg}$ of $\mathrm{Fe}_{3} \mathrm{O}_{4} @$ MIP NPs was added to $5.0 \mathrm{~mL}$ of LEV solution $\left(100 \mathrm{mg} \mathrm{L}^{-1}\right)$ with a contact time of $30 \mathrm{~min}$ and $\mathrm{pH}$ adjusted at 7.0.

The quantity $(Q)$ of the template bound to $\mathrm{Fe}_{3} \mathrm{O}_{4} @$ MIPs or $\mathrm{Fe}_{3} \mathrm{O}_{4} @$ NIPs was calculated according to the following equation: ${ }^{8}$

$$
Q_{t}=\left(C_{0}-C_{t}\right) \times V / W
$$

where $C_{0}$ and $C_{t}\left(\mathrm{mg} \mathrm{L}^{-1}\right)$ are the initial concentration and the residual concentration of $\mathrm{LEV}$ at time $(t)$, respectively; $V(\mathrm{~L})$ is the initial volume of the solution, and $W(\mathrm{~g})$ is the weight of the $\mathrm{Fe}_{3} \mathrm{O}_{4} @$ MIPs or $\mathrm{Fe}_{3} \mathrm{O}_{4} @$ NIPs.

Also, the amount of LEV extracted was expressed in percentage $(R, \%)$ and calculated using the equation $R \%=$ $100\left(C_{0}-C_{t}\right) / C_{0}{ }^{41}$

\subsection{Isothermal binding experiments}

$25 \mathrm{mg}$ of $\mathrm{Fe}_{3} \mathrm{O}_{4} @ \mathrm{MIP}$ NPs were added to $5.0 \mathrm{~mL}$ acetonitrile (ACN) solution of LEV of various concentrations from 25 to $125 \mathrm{mg} \mathrm{L}^{-1}$ and incubated for $30 \mathrm{~min}$ at $25{ }^{\circ} \mathrm{C}$. The $\mathrm{Fe}_{3} \mathrm{O}_{4} @ \mathrm{MIP}$ NPs were collected by an external magnetic field, and the concentration of LEV in the supernatants was measured colorimetrically at $\lambda_{\max } 775 \mathrm{~nm}$.

\subsection{Kinetic adsorption experiments}

$25 \mathrm{mg}$ of $\mathrm{Fe}_{3} \mathrm{O}_{4} @$ MIP NPs were added to LEV solution $(5.0 \mathrm{~mL})$ of various concentrations $\left(25,50\right.$ and $\left.100 \mathrm{mg} \mathrm{L}^{-1}\right)$ and incubated at different time intervals $(0-30 \mathrm{~min})$ at $25{ }^{\circ} \mathrm{C}$. The supernatant and imprinted polymers were separated by an external magnetic field, and the concentration of LEV in the supernatants was measured colorimetrically at $\lambda_{\max } 775 \mathrm{~nm}$.

\subsection{Selectivity test}

To evaluate the selectivity of levetiracetam magnetic imprinted polymer, several co-administered drugs such as quetiapine fumarate $(\mathrm{QF})$ and clonazepam (CLO) were tested. The experiments were carried out by adding $25 \mathrm{mg}$ of $\mathrm{Fe}_{3} \mathrm{O}_{4} @ \mathrm{MIP}$ and $\mathrm{Fe}_{3} \mathrm{O}_{4} @ N I P$ NPs to $5.0 \mathrm{~mL}$ of investigated drugs standard solutions at a concentration of $100 \mathrm{mg} \mathrm{L}^{-1}$ separately and $\mathrm{pH}$ was adjusted at pH 7.0 using phosphate buffer solution. The solutions were shaken at $60 \mathrm{rpm}$ for $30 \mathrm{~min}$ at $25^{\circ} \mathrm{C}$ in a rotatory shaker. The supernatant of each drug and the magnetic imprinted polymers were separated by an external magnetic field and analyzed by UV-Vis spectroscopy.

\subsection{Molecularly imprinted magnetic solid-phase extraction (MI-MSPE) of LEV from plasma samples}

2.10.1 Calibration and control samples. A standard stock solution of LEV (1.0 mg mL $\mathrm{mL}^{-1}$ ) was prepared in ACN. Spiking solutions for calibration curve and quality controls (QC) were prepared by appropriate dilution in ACN. Spiking solutions (50 $\mu \mathrm{L})$ were added to drug-free human plasma $(950 \mu \mathrm{L})$ as a bulk, to obtain LEV spiking concentration levels of $10-80 \mu \mathrm{g} \mathrm{mL}{ }^{-1}$. Each validation run consisted of blank sample (a plasma sample processed without drug), calibration curve consisting of six nonzero samples covering a range of $10 \mu \mathrm{g} \mathrm{mL}^{-1}$ to $80 \mu \mathrm{g} \mathrm{mL} \mathrm{m}^{-1}$ and quality control (QC) samples; LLOQ $=7.5 \mu \mathrm{g} \mathrm{mL}{ }^{-1}, \mathrm{QCL}=15 \mu \mathrm{g}$ $\mathrm{mL}^{-1}, \mathrm{QCM}=4 \mu \mathrm{g} \mathrm{mL}^{-1}$ and $\mathrm{QCH}=70 \mu \mathrm{g} \mathrm{mL}^{-1}$. Validation experiments were done on three consecutive days and linearity was assessed by least square regression analysis. The acceptable calibration curve is expected to have a correlation coefficient $\left(R^{2}\right)$ of 0.999 or better. The acceptance criterion for each backcalculated standard concentration was $15 \%$ deviation from the nominal value except LLOQ, which was set at $20 \%$.

2.10.2. Sample processing. $1 \mathrm{~mL}$ of plasma samples spiked with known variable amounts of LEV standard solution was vortexed with $2.0 \mathrm{~mL}$ of ACN for $5.0 \mathrm{~min}$. The mixtures were then centrifuged for $15 \mathrm{~min}$ at $5000 \mathrm{rpm}$. The supernatants were totally pipetted and diluted to $5.0 \mathrm{~mL}$ with phosphate buffer where $\mathrm{pH}$ was adjusted at 7.0. Blank samples were prepared in the same way as above but without the LEV spiking step.

$50 \mathrm{mg}$ of $\mathrm{Fe}_{3} \mathrm{O}_{4} @$ MIP NPs was placed into a glass vial. Prior to each extraction, particles were conditioned with $1 \mathrm{~mL}$ ACN and $2 \mathrm{~mL}$ PBS (pH 7.0) and decanted under magnetic field. Then $5.0 \mathrm{~mL}$ of sample or standard LEV solution at $\mathrm{pH} 7.0$ was added and the resulting mixture was shaken for $30 \mathrm{~min}$ at room temperature. Next, the solution was decanted by applying external magnetic field. The separated particles were washed by $2.0 \mathrm{~mL}$ ACN to remove any possible interference. LEV was extracted from $\mathrm{Fe}_{3} \mathrm{O}_{4} @$ MIP NPs shell by eluting the adsorbent with $2.0 \mathrm{~mL} \mathrm{MeOH}$ by sonication for $10 \mathrm{~min}$. The desorbed solution was collected under an external magnetic field and was analyzed via two different techniques; HPLC assay and 
a colorimetric assay, to quantify the recovered analyte and compare the integrity of the two proposed techniques.

2.10.3. Method validation. Specificity of the proposed methods was determined using randomly selected six blank human plasma samples, which were collected under controlled conditions.

Within-batch and between-batch accuracy and precision were evaluated by analysis of six replicates of the QC samples on the same day and on three consecutive days, respectively. Recovery of LEV was assessed by comparing the mean peak area or the mean absorbance of six extracted QC samples to those prepared in post-extraction blank plasma. In addition, the process efficiency was evaluated by comparing the mean peak areas or mean absorbance of extracted QC samples to those of LEV standards prepared in pure solvent.

2.10.4. Chromatographic assay. Separation of eluted spiked plasma samples was carried out using a reversed phase Agilent $\mathrm{C}_{18}$ column $(250 \times 4.6 \mathrm{~mm}, 5 \mu \mathrm{m})$. (Agilent, USA) with a mobile phase of methanol : PBS ( $\mathrm{pH} 4.0$ adjusted with phosphoric acid) in the ratio of $25: 75$ and a flow rate of 1.5 $\mathrm{mL} \min ^{-1}$ at $25{ }^{\circ} \mathrm{C}$. Each component of the mobile phase was degassed before use in an ultrasonic bath for $10 \mathrm{~min}$. The detection wavelength was set to $205 \mathrm{~nm}$, injection volume was $20 \mu \mathrm{L}$ and a total run time of $8 \mathrm{~min}$. The retention time of LEV was 4.87 min under the described conditions.

2.10.5. Colorimetric assay. Eluted solutions of spiked plasma samples in methanol were transferred into $10 \mathrm{~mL}$ volumetric flasks. $0.5 \mathrm{~mL}$ of $1.0 \%(\mathrm{w} / \mathrm{v})$ ferric chloride and $0.5 \mathrm{~mL}$ of $0.2 \%(\mathrm{w} / \mathrm{v})$ potassium ferricyanide were added and final volume was made up to the mark with methanol. The colored product was formed immediately at room temperature. The absorbance of the samples was measured at $775 \mathrm{~nm}$ against the reagent blank prepared in the same manner.

\section{Results and discussion}

\subsection{Theoretical study of the template-monomer} interactions

Generally, typical imprinting protocol is tedious and time consuming where the selection of optimum imprinting conditions, like functional monomers and polymerization solvent, depends on trial and error method. Therefore, a computeraided study has been suggested as a rational and fast method to search for optimal imprinting conditions in order to improve the properties of the fabricated $\mathrm{Fe}_{3} \mathrm{O}_{4} @$ MIP NPs, as mentioned in the methods section, we optimized several $1: 1$ and $1: 2$ complexes in different solutions. Fig. 2 shows the optimized geometries of the most stable complexes between LEV and the five monomers. The figure shows the $1: 2$ complex for all of them except divinylbenzene which could not form any stable 1:2 complex. As to the 1:1 complexes for the other four monomers they were simply formed by dropping either of the two monomers in the $1: 2$ complex, resulting in two possibilities for each monomer.

The results for the $1: 1$ binding energy calculations are listed in Table S1. $\dagger$ For AAM and MAA, two 1:1 complexes were investigated and compared. For other monomers, the binding

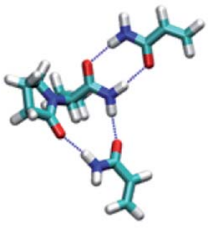

$A A M$

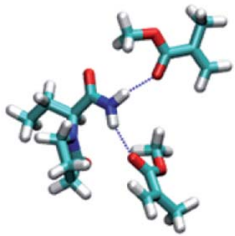

$M M A$

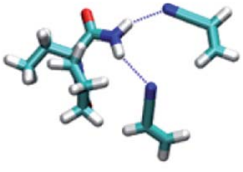

$A N$

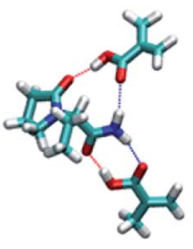

$M A A$

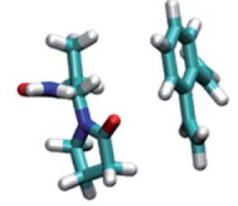

Fig. 2 Optimized geometries of the most stable complexes between LEV and acrylamide (AAM), methacrylic acid (MAA), methyl methacrylate (MMA), acrylonitrile (AN) and divinylbenzene (DVB) monomers.

energies for the optimum 1:1 complexes were too low to encourage further investigation of other $1: 1$ complex geometries.

As the table shows, the highest binding energies are between LEV and MAA followed by AAM. The best solvent appears to be chloroform followed by acetone in both cases. This makes sense because chloroform offers a very hydrophobic environment which encourages the drug and the monomer to cluster together and form mutual hydrogen bonds with their hydrophilic hydrogen bonding groups. Other monomers gave very low binding energies and were thus considered inappropriate for molecular imprinting.

After that we investigated the 1:2 complexes formed between LEV and the monomers. Table $\mathrm{S} 2 \uparrow$ shows the results of these calculations where DVB was not considered due to its very poor binding energies in 1:1 calculations. As the table suggests, the best binding energy is obtained at the $1: 2$ ratio between LEV and MAA in chloroform.

\subsection{Preparation of $\mathrm{Fe}_{3} \mathrm{O}_{4}$ @MIP nanoparticles for LEV extraction}

The fabrication technique of $\mathrm{Fe}_{3} \mathrm{O}_{4} @ M I P$ NPs constituted a multistep approach. $\mathrm{Fe}_{3} \mathrm{O}_{4} @ \mathrm{OA}$ NPs were synthesized via a wet chemical co-precipitation technique. Oleic acid as surface modifier is very crucial for the successful creation of the $\mathrm{SiO}_{2}$ shell. ${ }^{12}$ The surface of $\mathrm{Fe}_{3} \mathrm{O}_{4} @ O A$ NPs was then coated with silica by TEOS. The $\mathrm{SiO}_{2}$ shell provided a hydrophilic and biocompatible surface, and prevented oxidation of $\mathrm{Fe}_{3} \mathrm{O}_{4} \cdot{ }^{42}$ Moreover, the silanol groups allowed the existence of extra functional groups on the $\mathrm{Fe}_{3} \mathrm{O}_{4} @ \mathrm{SiO}_{2}$ surface. Thus, double bonds were introduced onto $\mathrm{Fe}_{3} \mathrm{O}_{4} @ \mathrm{SiO}_{2}$ using MPS to ensure firm growth of the imprinted layer. ${ }^{42}$ Finally $\mathrm{Fe}_{3} \mathrm{O}_{4}$ @MIPs NPs were synthesized using the modified $\mathrm{Fe}_{3} \mathrm{O}_{4}$ NPs, MAA as monomer, EGDMA as crosslinker, levetiracetam as template 
and AIBN as initiator in chloroform as porogenic solvent. The resultant $\mathrm{Fe}_{3} \mathrm{O}_{4} @$ @IP NPs provided access to the recognition sites of LEV and can be easily separated using an external magnetic field thus can be used as a clean-up technique in human plasma assay.

\subsection{Characterization of $\mathrm{Fe}_{3} \mathrm{O}_{4} @ M I P$ nanoparticles}

3.3.1. TEM. The size and shape of $\mathrm{Fe}_{3} \mathrm{O}_{4}, \mathrm{Fe}_{3} \mathrm{O}_{4} @ \mathrm{SiO}_{2}$, $\mathrm{Fe}_{3} \mathrm{O}_{4} @$ MPS and $\mathrm{Fe}_{3} \mathrm{O}_{4} @$ @IP NPs were examined by TEM. It can be observed that the mean diameter of $\mathrm{Fe}_{3} \mathrm{O}_{4} @ \mathrm{OA}$ NPs was about $9 \mathrm{~nm}$ (Fig. 3[a]). After modifying $\mathrm{Fe}_{3} \mathrm{O}_{4} @ \mathrm{OA}$ with $\mathrm{SiO}_{2}$ (Fig. 3[b]), the diameter of the $\mathrm{Fe}_{3} \mathrm{O}_{4} @ \mathrm{SiO}_{2} \mathrm{NPs}$ increased to approximately $17 \mathrm{~nm}$, corresponding to $8 \mathrm{~nm}$ thickness of the $\mathrm{SiO}_{2}$ layer on the surface of $\mathrm{Fe}_{3} \mathrm{O}_{4}$ NPs. Double bond modified $\mathrm{Fe}_{3} \mathrm{O}_{4} @$ MPS NPs diameter is further increased to $24 \mathrm{~nm}$ (Fig. 3 [c]) indicating that the coupling of MPS on the $\mathrm{Fe}_{3} \mathrm{O}_{4}$ surface was successful. After polymerization with LEV as the template, $\mathrm{Fe}_{3} \mathrm{O}_{4} @$ MIP particle size increased to about 250-300 nm (Fig. 3 [d]) and you can see the obvious core-shell junction structure which facilitates the mass transfer process between $\mathrm{Fe}_{3} \mathrm{O}_{4} @ \mathrm{MIP}$ NPs surface and solution.

3.3.2. SEM. The nature of the $\mathrm{Fe}_{3} \mathrm{O}_{4} @ \mathrm{MIP}$ and $\mathrm{Fe}_{3} \mathrm{O}_{4} @ \mathrm{NIP}$ NPs was evaluated by SEM (Fig. 4). It was observed that the surface of the $\mathrm{Fe}_{3} \mathrm{O}_{4} @$ MIP NPs is uneven with many holes; thus facilitating the adsorption of template molecule; LEV. On the other hand, the surface of $\mathrm{Fe}_{3} \mathrm{O}_{4} @$ NIP NPs is smooth, thus lacking effective adsorption sites.

3.3.3. Energy-dispersive X-ray spectroscopy (EDX). EDX analysis was performed to confirm that polymerization took place. EDX spectra (Fig. 5) indicated the presence of $\mathrm{Fe}, \mathrm{Si}, \mathrm{O}$ and $\mathrm{C}$, confirming that polymerization occurred on the surface of $\mathrm{Fe}_{3} \mathrm{O}_{4} @$ MPS NPs.
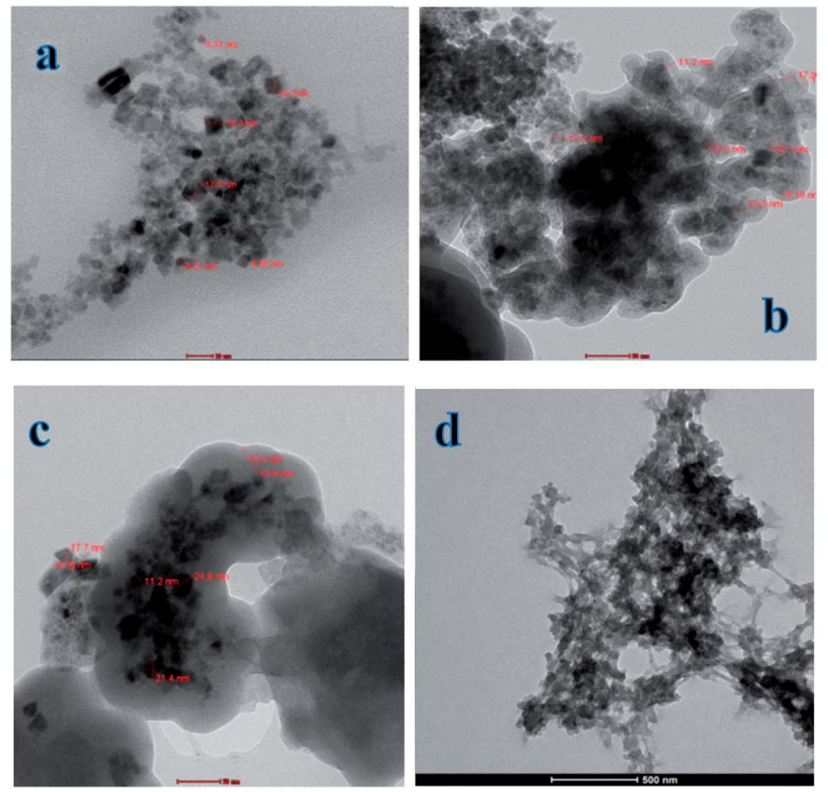

Fig. 3 TEM images of: [a] $\mathrm{Fe}_{3} \mathrm{O}_{4} \mathrm{aOA} \mathrm{NPs}$, [b] $\mathrm{Fe}_{3} \mathrm{O}_{4} \mathrm{aSiO}_{2} \mathrm{NPs}$, [c] $\mathrm{Fe}_{3} \mathrm{O}_{4}$ @MPS NPs and [d] $\mathrm{Fe}_{3} \mathrm{O}_{4}$ @MIP NPs.
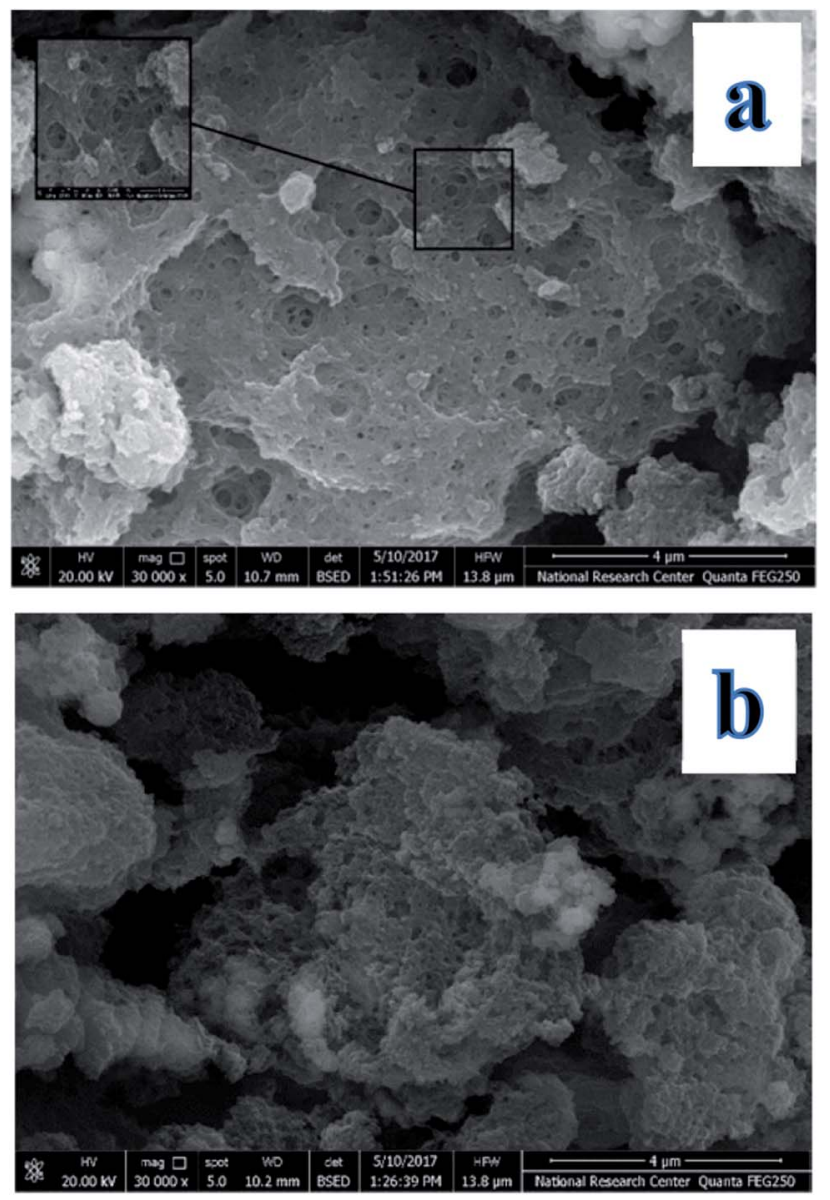

Fig. 4 SEM images of: [a] $\mathrm{Fe}_{3} \mathrm{O}_{4} @$ MIP NPs and [b] $\mathrm{Fe}_{3} \mathrm{O}_{4}$ @NIP NPs.

3.3.4. XRD. Structural and chemical properties of synthesized $\mathrm{Fe}_{3} \mathrm{O}_{4} @ M I P$ NPs were evaluated using X-ray diffraction (XRD). As shown in Fig. 6, XRD patterns of the synthesized $\mathrm{Fe}_{3} \mathrm{O}_{4}, \mathrm{Fe}_{3} \mathrm{O}_{4} @ \mathrm{SiO}_{2}, \mathrm{Fe}_{3} \mathrm{O}_{4} @ M P S$ and $\mathrm{Fe}_{3} \mathrm{O}_{4} @$ @IP NPs displayed several strong reflection peaks in the $2 \theta$ region of $20-70^{\circ}$.

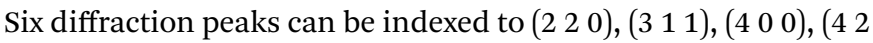
2), ( $\left.\begin{array}{lll}5 & 1 & 1\end{array}\right)$ and ( $\left.\begin{array}{lll}4 & 4 & 0\end{array}\right)$, which match well with the database of magnetite in JCPDS (JCPDS card: 19-629) file. The XRD patterns also indicated that the synthesized polymeric particles are crystalline in shape.

3.3.5. FTIR. The products of $\mathrm{Fe}_{3} \mathrm{O}_{4}, \mathrm{Fe}_{3} \mathrm{O}_{4} @ \mathrm{SiO}_{2}, \mathrm{Fe}_{3} \mathrm{O}_{4} @$ MPS, and $\mathrm{Fe}_{3} \mathrm{O}_{4}$ @MIPs were investigated by FT-IR spectroscopy (Fig. 7). The characteristic absorption bands at $576.6 \mathrm{~cm}^{-1}$ were attributed to the Fe-O stretching vibration (Fig. 7[a]) and the

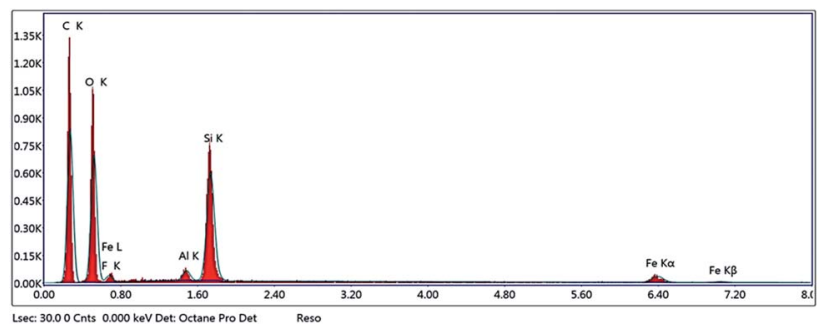

Fig. 5 EDX of $\mathrm{Fe}_{3} \mathrm{O}_{4}$ @MIP NPs. 


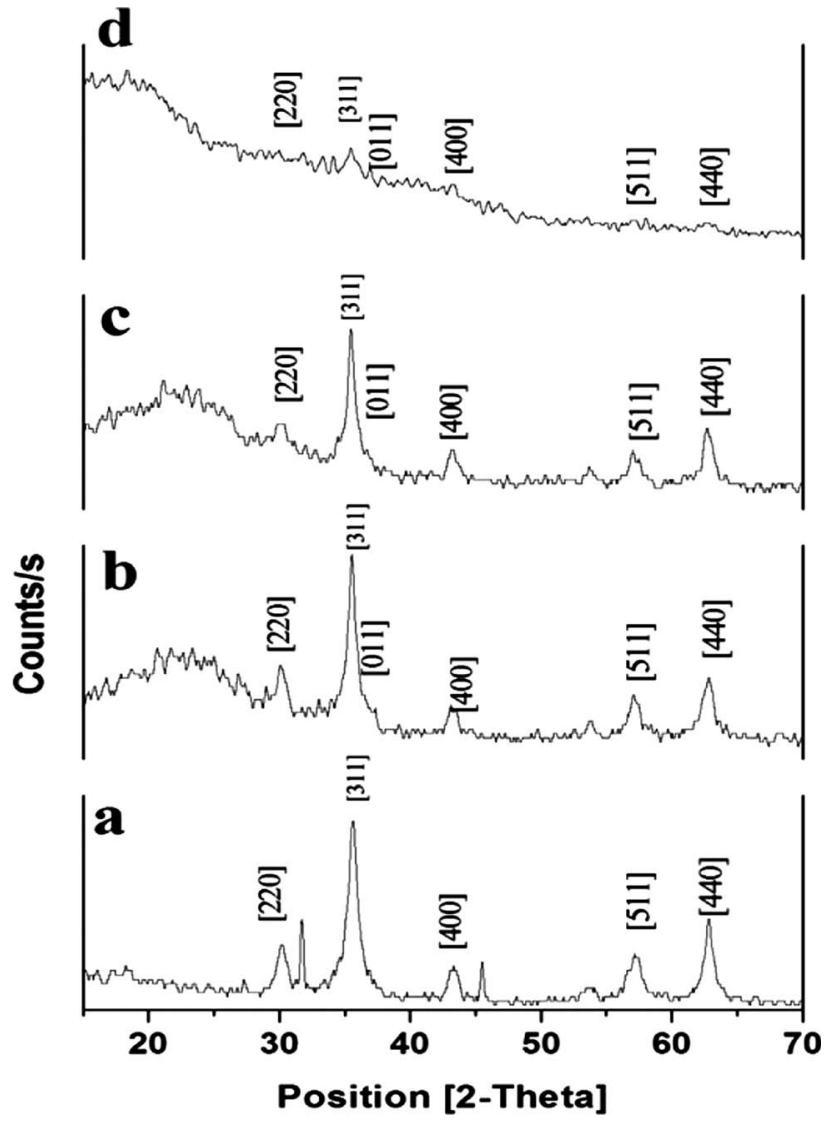

Fig. 6 XRD patterns of: [a] $\mathrm{Fe}_{3} \mathrm{O}_{4} @ \mathrm{aOA} N P s$, [b] $\mathrm{Fe}_{3} \mathrm{O}_{4} \mathrm{aSiO}_{2} \mathrm{NPs}$, [c] $\mathrm{Fe}_{3} \mathrm{O}_{4}$ @MPS NPs and [d] $\mathrm{Fe}_{3} \mathrm{O}_{4} @$ @MIP NPs.

C-H stretching vibrations of oleic acid were indicated by an absorption band at $2924.5 \mathrm{~cm}^{-1}$. ${ }^{8}$ After modification of $\mathrm{SiO}_{2}$ on $\mathrm{Fe}_{3} \mathrm{O}_{4} @ \mathrm{OA}$ NPs surface, the $\mathrm{Si}-\mathrm{O}-\mathrm{Si}$ stretching vibration was observed at $1097.3 \mathrm{~cm}^{-1}$ and $\mathrm{OH}$ group at $1632.5 \mathrm{~cm}^{-1}$ and $3832.8 \mathrm{~cm}^{-1}$ (Fig. 7[b]) indicating the formation of silica coating on the surface of $\mathrm{Fe}_{3} \mathrm{O}_{4} @ \mathrm{OA} \mathrm{NPs.}{ }^{13}$ As can be seen from Fig. 7 [c] stretching vibrations of $\mathrm{C}-\mathrm{H}$ at $2928 \mathrm{~cm}^{-1}$ and $2854 \mathrm{~cm}^{-1}$ together with the absorption band appearing at $1632.5 \mathrm{~cm}^{-1}$ indicated $\mathrm{C}=\mathrm{C}$ double bond formation and that MPS had successfully modified $\mathrm{Fe}_{3} \mathrm{O}_{4} @ \mathrm{SiO}_{2}$ surface. ${ }^{43}$ Also the peaks of $\mathrm{C}-\mathrm{O}$ group at $1259.3 \mathrm{~cm}^{-1}$ and $\mathrm{C}=\mathrm{O}$ group at $1727.9 \mathrm{~cm}^{-1}$ and $\mathrm{C}-\mathrm{H}$ group of methyl at $2924.5 \mathrm{~cm}^{-1}$ indicated that the methacrylic acid layer was formed on the surface of $\mathrm{Fe}_{3} \mathrm{O}_{4} @ M P S$ NPs (Fig. 7[d]) and thus confirmed the successful preparation of $\mathrm{Fe}_{3} \mathrm{O}_{4} @$ @IPs NPs. ${ }^{13}$

3.3.6. VSM. The magnetic properties of $\mathrm{Fe}_{3} \mathrm{O}_{4} @ M I P$ NPs were studied by VSM. The magnetic hysteresis loops of $\mathrm{Fe}_{3} \mathrm{O}_{4}$, $\mathrm{Fe}_{3} \mathrm{O}_{4} @ \mathrm{SiO}_{2}, \quad \mathrm{Fe}_{3} \mathrm{O}_{4} @ M P S$ and $\mathrm{Fe}_{3} \mathrm{O}_{4} @$ @MIP NPs at room temperature are shown in Fig. 8. Obviously, there is no hysteresis, both remanence and coercivity are almost zero, suggesting that the prepared NPs are superparamagnetic. ${ }^{9}$ The saturation magnetization values of the prepared $\mathrm{Fe}_{3} \mathrm{O}_{4}, \mathrm{Fe}_{3} \mathrm{O}_{4} @ \mathrm{SiO}_{2}, \mathrm{Fe}_{3}$ $\mathrm{O}_{4} @$ @MPS and $\mathrm{Fe}_{3} \mathrm{O}_{4} @$ @MIP NPs were 36.7, 12.3, 8.4 and $5.0 \mathrm{emu}$ $\mathrm{g}^{-1}$, respectively. Thus, it can be concluded that the magnetization values decreased with increasing the number of nonmagnetic coating layers on the surface of $\mathrm{Fe}_{3} \mathrm{O}_{4}$ NPs.

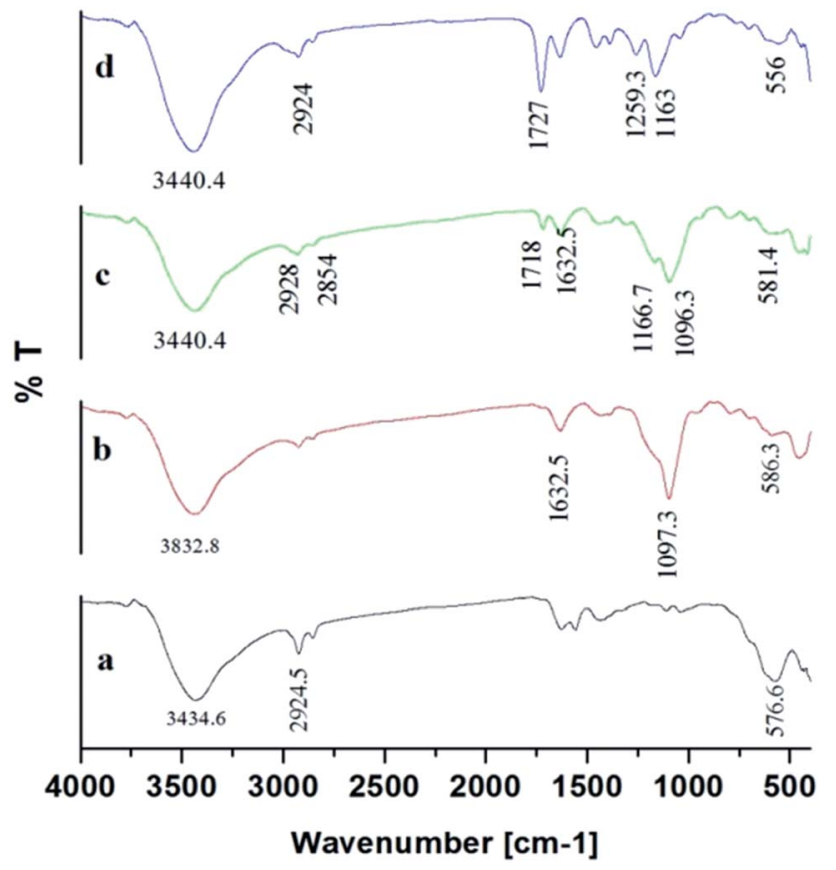

Fig. 7 FTIR spectra of: [a] $\mathrm{Fe}_{3} \mathrm{O}_{4} @ \mathrm{aOA} N P s$, [b] $\mathrm{Fe}_{3} \mathrm{O}_{4} \mathrm{QSiO}_{2} \mathrm{NPs}$, [c] $\mathrm{Fe}_{3} \mathrm{O}_{4} @$ aMPS NPs and [d] $\mathrm{Fe}_{3} \mathrm{O}_{4}$ @MIP NPs.

$\mathrm{Fe}_{3} \mathrm{O}_{4} @$ MIP NPs showed the least saturation magnetization yet, it can be separated using an external magnetic field..$^{\mathbf{4 3 4}}$

\subsection{Analysis techniques}

3.4.1. Colorimetric method for binding experiments. The proposed colorimetric method for determination of LEV is based on the reduction of the $\mathrm{Fe}^{3+}$ in $\mathrm{FeCl}_{3}$ to $\mathrm{Fe}^{2+}$ by the drug in the presence of $\mathrm{K}_{3} \mathrm{Fe}\left(\mathrm{CN}_{6}\right)$. Consequently, the in situ formed $\mathrm{Fe}^{2+}$ reacts with $\mathrm{K}_{3} \mathrm{Fe}\left(\mathrm{CN}_{6}\right)$ under acidic conditions to form soluble Prussian blue ( $\left.\mathrm{KF}\left[\mathrm{Fe}_{2}\left(\mathrm{CN}_{6}\right)\right]\right)$ whose absorbance can be measured at $775 \mathrm{~nm}$ against the corresponding reagent blank. ${ }^{45}$ The method was validated according to $\mathrm{ICH}$ guidelines for

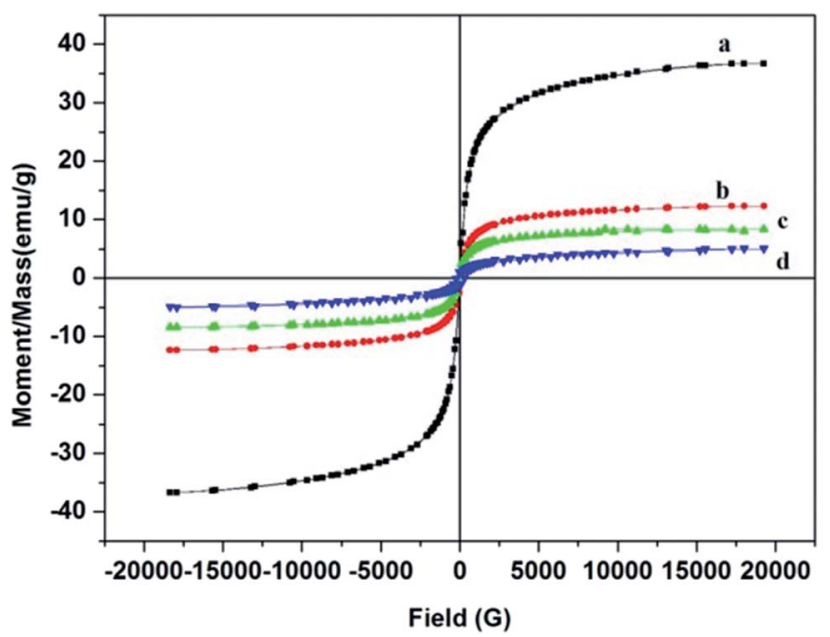

Fig. 8 Hysteresis loop of: [a] $\mathrm{Fe}_{3} \mathrm{O}_{4} @ \mathrm{aOA} N P s$, [b] $\mathrm{Fe}_{3} \mathrm{O}_{4}\left(\mathrm{aSiO}_{2} \mathrm{NPs}\right.$, [c] $\mathrm{Fe}_{3} \mathrm{O}_{4} @$ @MPS NPs and [d] $\mathrm{Fe}_{3} \mathrm{O}_{4} @$ @MIP NPs. 
validation of analytical procedures and the validation results are illustrated in Table S3. $\dagger$

3.4.2. Spectrophotometric method for binding experiments. The wavelength of maximum absorption $\left(\lambda_{\max }\right)$ was determined for the studied drugs (QF $245 \mathrm{~nm}$ and CLO $250 \mathrm{~nm}$ ). The method was validated according to $\mathrm{ICH}$ guidelines for validation of analytical procedures regarding linearity, accuracy, precision (within and between days), limit of detection (LOD), and limit of quantification (LOQ). ${ }^{\mathbf{3 8 - 4 0}}$ The validation results are summarized in Table S3. $\uparrow$ Results indicated the suitability of the assay for accurate determination of the studied drugs in neat solvent for optimization purposes.

\subsection{Optimization of the MI-MSPE procedure}

To attain the best conditions for extraction of the target drug; LEV, various factors such as extraction solvent, extraction time, $\mathrm{pH}$ and amount of adsorbent were studied and optimized for LEV pre-concentration and clean-up.

3.5.1. Extraction solvent. To find a suitable solvent for the rebinding of the template molecule LEV, several types of solvents were investigated (Fig. 9). Upon the use of chloroform (synthesis solvent) and dichloromethane, almost no difference between $\mathrm{Fe}_{3} \mathrm{O}_{4} @ \mathrm{MIP}$ and $\mathrm{Fe}_{3} \mathrm{O}_{4} @$ NIP NPs in extraction efficiency was found and this can be attributed to the formation of aggregates of the imprinted particles upon contact with these solvents leading to extraction by clogging effect rather than by adsorption. The results also showed that the addition of water or methanol disturbed the specific binding effect of the $\mathrm{Fe}_{3}$ $\mathrm{O}_{4} @$ MIP NPs, most probably because the strong polarity of water or methanol destroyed the hydrogen bond between the $\mathrm{Fe}_{3} \mathrm{O}_{4} @$ MIP NPs and LEV. ${ }^{5}$ Nevertheless, ACN showed the best result in extraction and specificity and therefore was used in further studies.

3.5.2. Extraction time. The effect of extraction time on the extraction efficiency of LEV (100 mg L ${ }^{-1}$ ) on 150 mg $\mathrm{Fe}_{3} \mathrm{O}_{4} @$ MIP NPs in $30 \mathrm{~mL}$ ACN was studied in the range of 10-210 min. The optimum extraction was accomplished within $30 \mathrm{~min}$, while

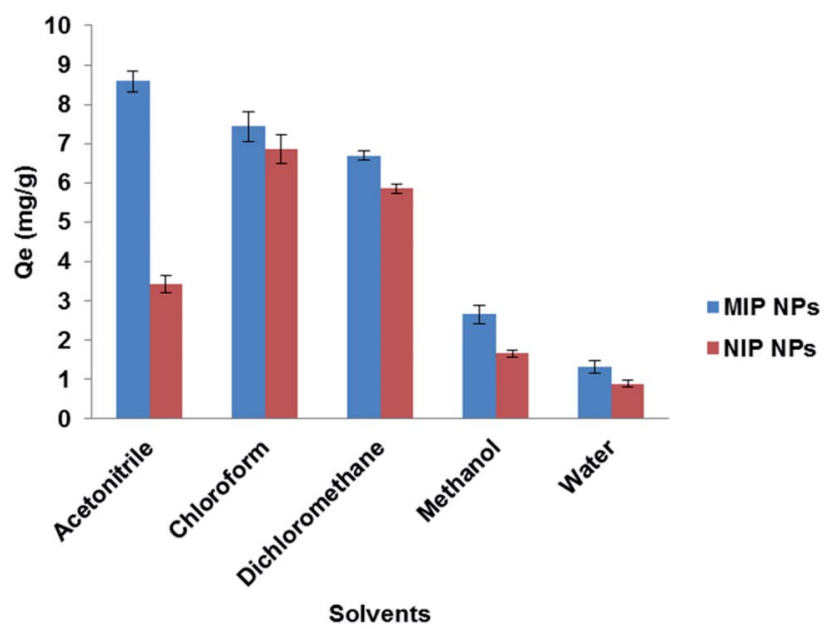

Fig. 9 Effect of different solvents on the extraction of LEV by $\mathrm{Fe}_{3}$ $\mathrm{O}_{4} @$ MIP NPs and $\mathrm{Fe}_{3} \mathrm{O}_{4}$ @NIP NPs. longer contact times showed no further increase in the extraction efficiency (Fig. 10). The reason behind this is that at prolonged contact time, equilibrium was already attained on the surface of $\mathrm{Fe}_{3} \mathrm{O}_{4} @$ @IP NPs resulting in no further extraction of LEV from the extraction solvent. ${ }^{37}$ In addition, $30 \mathrm{~min}$ is considered a short extraction time and this can be attributed to the good dispersion of $\mathrm{Fe}_{3} \mathrm{O}_{4} @$ MIP NPs in the extraction solvent thus increasing the exposed surface area of the $\mathrm{Fe}_{3} \mathrm{O}_{4} @$ @IP NPs for contact with target molecule; LEV. ${ }^{37}$ Based on the obtained results, an extraction of $30 \mathrm{~min}$ was adopted.

3.5.3. Effect of $\mathbf{p H}$. $\mathrm{pH}$ of the sample solution played an important role in LEV adsorption by $\mathrm{Fe}_{3} \mathrm{O}_{4} @$ MIP NPs. The carboxylic acid incorporated in the cavities of the $\mathrm{Fe}_{3} \mathrm{O}_{4} @ \mathrm{MIP}$ NPs has very high hydrophilic affinity with respect to LEV. ${ }^{46}$ In addition, the amine group of LEV also possesses hydrogen bonding with the carboxylic acid group of the $\mathrm{Fe}_{3} \mathrm{O}_{4} @$ @IP NPs. Thus, the extent of LEV extraction depends on its interaction with carboxylic groups of the $\mathrm{Fe}_{3} \mathrm{O}_{4} @$ @IP NPs. To evaluate the effect of $\mathrm{pH}$, a working solution with different $\mathrm{pHs}$ in the range of 3.0-11.0 was studied. As shown in Fig. 11, the highest adsorption capacity of LEV by $\mathrm{Fe}_{3} \mathrm{O}_{4} @$ MIP NPs was at pH 7.0 and lesser adsorption was observed at lower and higher $\mathrm{pH}$ values. It can be estimated that at $\mathrm{pH} 7.0$ the carboxyl groups of $\mathrm{Fe}_{3} \mathrm{O}_{4} @$ MIP NPs were deprotonated while LEV functional groups become protonated thus allowing smooth interaction between LEV and the $\mathrm{Fe}_{3} \mathrm{O}_{4} @$ MIP NPs. ${ }^{46}$ Therefore, the pH 7.0 was selected as optimized $\mathrm{pH}$ according to the findings of the present study.

3.5.4. Effect of adsorbent amount. To investigate the optimum amount $\mathrm{Fe}_{3} \mathrm{O}_{4}$ @MIP NPs on the extraction efficiency of LEV (100 $\left.\mathrm{mg} \mathrm{L}^{-1}\right)$ in $5 \mathrm{~mL}$ ACN under the optimized conditions, various amounts of $\mathrm{Fe}_{3} \mathrm{O}_{4}$ @MIP NPs were studied from 25 to $200 \mathrm{mg}$. The results shown in Fig. 12 indicate that the recovery of LEV has increased following an increase in the $\mathrm{Fe}_{3} \mathrm{O}_{4} @$ MIP NPs amount up to $50 \mathrm{mg}$ due to the increase in available adsorption sites. Further increase in the amount of $\mathrm{Fe}_{3} \mathrm{O}_{4} @ M I P$ NPs showed no significant increase in the extraction yields of LEV. Thus, a $50 \mathrm{mg}$ amount was used as the optimum amount of $\mathrm{Fe}_{3} \mathrm{O}_{4} @$ MIP NPs.

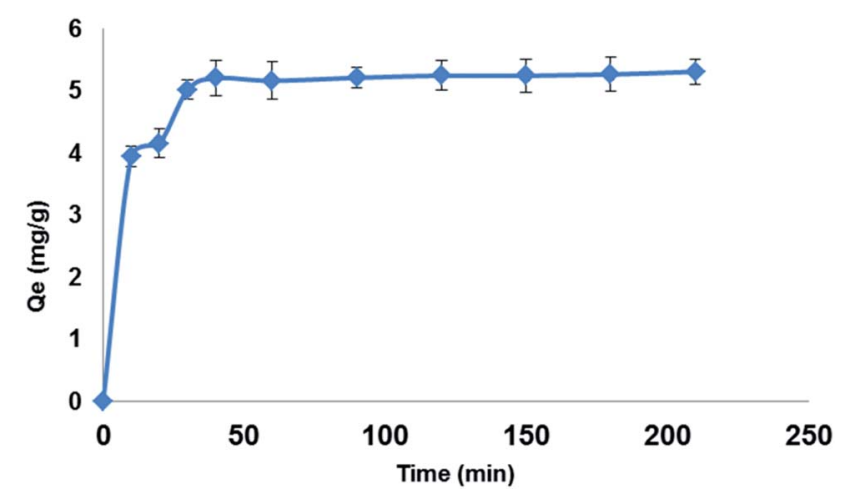

Fig. 10 Effect of extraction time on the adsorption capacity $\left(q_{t}\right)$ of LEV onto $\mathrm{Fe}_{3} \mathrm{O}_{4}$ @MIP NPs; adsorbent: $150 \mathrm{mg}$, drug conc. $100 \mathrm{mg} \mathrm{L}^{-1}$, temperature: $25^{\circ} \mathrm{C}, \mathrm{pH}$ : natural $\mathrm{pH}$ of LEV, time: $210 \mathrm{~min}$. 


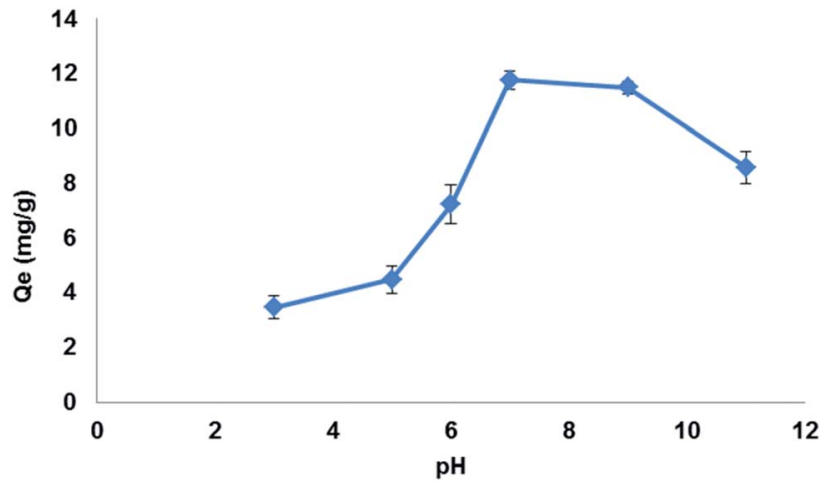

Fig. 11 Effect of $\mathrm{pH}$ on the adsorption capacity $\left(q_{\mathrm{e}}\right)$ of LEV onto $\mathrm{Fe}_{3}-$ $\mathrm{O}_{4}$ @MIP NPs. Adsorbent: $25 \mathrm{mg}$, drug conc. $100 \mathrm{mg} \mathrm{L}^{-1}$, temperature: $25^{\circ} \mathrm{C}$, time: $30 \mathrm{~min}$.

\subsection{Adsorption isotherms}

Results of equilibrium studies were analyzed using Langmuir, Freundlich and Sips isotherms to find the best fitted model that can describe the adsorption process.

The original forms of the Langmuir, ${ }^{47}$ Freundlich $^{48}$ and $\operatorname{Sips}^{49}$ isotherms are given by eqn (1), (2), and (3) respectively,

$$
\begin{gathered}
q_{\mathrm{e}}=\frac{Q_{0} b C_{\mathrm{e}}}{\left(1+b C_{\mathrm{e}}\right)} \\
q_{\mathrm{e}}=K_{\mathrm{f}} C_{\mathrm{e}^{n}}^{\frac{1}{n}} \\
q_{\mathrm{e}}=\frac{Q_{\mathrm{m}} K_{\mathrm{s}} C_{\mathrm{e}^{n}}^{\frac{1}{n}}}{1+K_{\mathrm{s}} C_{\mathrm{e}^{\frac{1}{n}}}^{\frac{1}{n}}}
\end{gathered}
$$

where $C_{\mathrm{e}}$ is the equilibrium concentration of LEV in solution $\left(\mathrm{mg} \mathrm{mL}^{-1}\right), q_{\mathrm{e}}$ is the amount of LEV adsorbed per unit mass of adsorbent $\left(\mathrm{mg} \mathrm{g}^{-1}\right)$, at equilibrium concentration, $C_{\mathrm{e}}, b$ is the Langmuir equilibrium constant $\left(\mathrm{mL} \mathrm{mg}^{-1}\right) . Q_{0}$ signifies the maximum adsorption capacity $\left(\mathrm{mg} \mathrm{g}^{-1}\right), K_{\mathrm{f}}$ and $1 / n$ are Freundlich constants where $n$ is related to the adsorption intensity, and $K_{\mathrm{f}}\left(\mathrm{mg}^{1-1 / n} \mathrm{~mL}^{1 / n} \mathrm{~g}^{-1}\right)$ indicates the adsorption capacity. $Q_{\mathrm{m}}$ is the maximum adsorption capacity calculated by Sips ( $\left.\mathrm{mg} \mathrm{g}^{-1}\right), K_{\mathrm{s}}$ is the Sips constant $\left(\mathrm{mL} \mathrm{mg}^{-1}\right)$ and $n$ is the Sips model exponent.

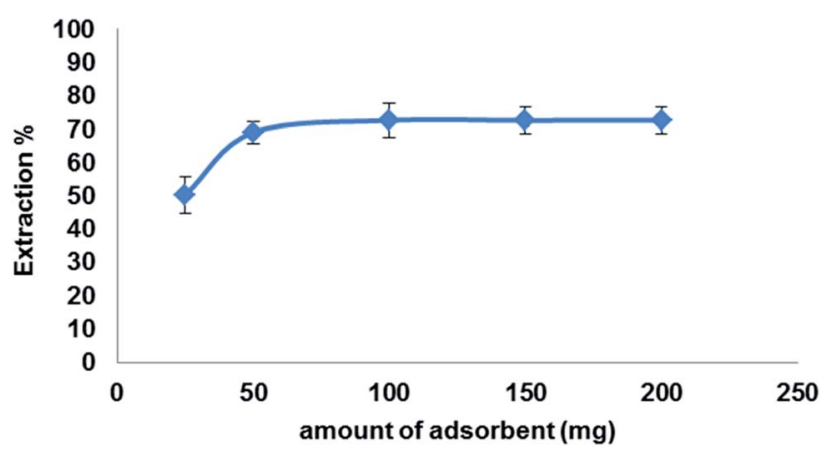

Fig. 12 Effect of adsorbent amount on the extraction efficiency of LEV onto $\mathrm{Fe}_{3} \mathrm{O}_{4}$ @MIP NPs; drug conc. $100 \mathrm{mg} \mathrm{L}^{-1}$, temperature: $25^{\circ} \mathrm{C}, \mathrm{pH}$ : 7.0, time: $30 \mathrm{~min}$.
Corresponding linear forms of Langmuir and Freundlich isotherms can be expressed in eqn (4) and (5), respectively, ${ }^{\mathbf{4 7}, 50}$

$$
\begin{gathered}
\frac{C_{\mathrm{e}}}{q_{\mathrm{e}}}=\frac{1}{b Q_{0}}+\frac{C_{\mathrm{e}}}{Q_{0}} \\
\ln q_{\mathrm{e}}=\ln K_{\mathrm{f}}+\left(\frac{1}{n}\right) \ln C_{\mathrm{e}}
\end{gathered}
$$

As shown in Fig. S4[a], [b] and [c], $\dagger$ the data were fitted by Langmuir, Freundlich, and Sips models respectively. It was observed that the equilibrium data were best matched by Langmuir isotherm with good correlation coefficient and $\chi^{2}$ values. The detailed values are reported in Table 1.

\subsection{Adsorption kinetics}

The kinetic data obtained were evaluated using pseudo-firstorder and pseudo-second-order kinetics equations.

The kinetic data obtained were evaluated using pseudo-firstorder and pseudo-second-order kinetics eqn (6) and (7) respectively. ${ }^{51,52}$

$$
\begin{gathered}
\log \left(q_{1}-q_{t}\right)=\log q_{1 e}-\frac{K_{1} t}{2.303} \\
\frac{t}{q_{t}}=\frac{1}{K_{2} q_{\mathrm{e}}^{2}}+\frac{t}{q_{\mathrm{e}}}
\end{gathered}
$$

where $q_{\mathrm{e}}$ and $q_{t}\left(\mathrm{mg} \mathrm{g}^{-1}\right)$ are the amounts of LEV adsorbed on $\mathrm{Fe}_{3} \mathrm{O}_{4} @$ MIP NPs at equilibrium and at time $t$ (min), respectively. $K_{1}$ is the pseudo-first-order kinetics constant $\left(\mathrm{min}^{-1}\right)$ and $K_{2}$ is the pseudo-second-order kinetics constant ( $\mathrm{g}$ $\left.\mathrm{mg}^{-1} \min ^{-1}\right)$.

All the linear regression correlation coefficients and rate constants of adsorption are presented in Table 2. The second-order model was more suitable to describe the kinetic data than the firstorder model because of the favorable fit between experimental and calculated values of $q_{\mathrm{e}}$ in the second-order model (all $R^{2}$ values are above 0.999 at different initial concentrations). The plots of the experimental data of the sorption capacity against time for the pseudo-first-order and pseudo-second-order model were shown in Fig. S5[a] and [b], $\uparrow$ respectively. It can be seen from Fig. $\mathrm{S} 5 \dagger$ that the equilibrium adsorption amount increased with an increase of initial LEV concentration.

\subsection{Study of $\mathrm{Fe}_{3} \mathrm{O}_{4} @ M I P$ NPs selectivity}

In order to evaluate the selectivity of the synthesized $\mathrm{Fe}_{3} \mathrm{O}_{4} @$ @MIP NPs, extraction of LEV and its co-administered drugs; QF and CLO, was evaluated. The initial concentration of drugs (5.0 $\mathrm{mL}, 100 \mathrm{mg} \mathrm{L}^{-1}$ ) was extracted by $50 \mathrm{mg}$ of $\mathrm{Fe}_{3} \mathrm{O}_{4} @$ MIP NPs and $\mathrm{Fe}_{3} \mathrm{O}_{4} @$ @IP NPs at $\mathrm{pH}$ 7.0. The partition coefficient $K$ was determined according to the following equation: ${ }^{13}$

$$
K=C_{\mathrm{p}} / C_{\mathrm{s}}
$$

where $C_{\mathrm{p}}$ is the amount of LEV bound by $\mathrm{Fe}_{3} \mathrm{O}_{4}$ @MIP or $\mathrm{Fe}_{3}$ $\mathrm{O}_{4} @$ NIP NPs and $C_{\mathrm{s}}$ is the concentration of LEV remaining in solution. 
3.9.3. Colorimetric assay. Spectrophotometry may be used in both qualitative and quantitative assays. However, one of the major problems in applying spectrophotometry to complex matrices is that it is not a selective technique as most endogenous compounds mainly absorb in the UV part of the spectrum. ${ }^{56}$ On the other hand, visible spectrophotometry (colorimetry) is the first reliable quantitative method used for drug/metabolite analysis in blood. ${ }^{56}$ Such analysis can be performed through a chromogenic reaction directly in the sample with the condition of appropriate sample treatment including protein precipitation, solvent extraction or micro diffusion. ${ }^{\mathbf{5 6}}$

One of the colorimetric methods that have been applied for analysis of drugs in biological fluids is the potassium ferricyanide colorimetric assay. ${ }^{57,58}$ Such assay has been applied for the determination of LEV in its dosage form and was found to be a reliable method for LEV quantitative analysis. ${ }^{45}$ Fig. $\mathrm{S} 7 \dagger$ illustrates the absorption spectra of free and spiked plasma samples at different concentrations of LEV after reaction with potassium ferricyanide. It can be observed that the blank plasma has no significant effect on potassium ferricyanide reaction where the absorbance at $\lambda_{\max }$ is almost zero. Nevertheless, spiked plasma samples showed absorption spectra with varying intensities according to LEV concentration indicating that LEV is the one interacting with potassium ferricyanide and no interference from endogenous plasma components was found. Such results confirmed the findings of the HPLC chromatograms indicating that $\mathrm{Fe}_{3} \mathrm{O}_{4} @$ MIP NPs allowed the extraction of LEV from human plasma samples with complete suppression of any other endogenous compound in the sample matrix thus omitted the problem of interference and supported the applicability of the proposed colorimetric assay for the determination of LEV in human plasma samples.

3.9.4. HPLC and colorimetric assays validation. A comparison was performed between the two proposed assays (HPLC and colorimetry) to evaluate the applicability of the colorimetric assay for the determination of LEV in human plasma samples after MI-MSPE using $\mathrm{Fe}_{3} \mathrm{O}_{4} @$ @IP NPs.

I. Selectivity. Analysis of six batches of blank plasma and comparison to fortified plasma samples showed the absence of interference at LEV's retention time for HPLC assay and $\lambda_{\max }$ of LEV's complex with potassium ferricyanide for the colorimetric assay. The chromatograms and the absorbance curves obtained

Table 4 Accuracy and precision for the determination of LEV via HPLC and colorimetric assays

\begin{tabular}{|c|c|c|c|c|}
\hline & \multicolumn{2}{|l|}{ HPLC assay } & \multicolumn{2}{|c|}{ Colorimetric assay } \\
\hline & $\begin{array}{l}\text { Within } \\
\text { run }\end{array}$ & Between run & Within run & Between run \\
\hline & $\begin{array}{l}\text { Mean recoveryo } \\
\pm \mathrm{RSD} \%\end{array}$ & & $\begin{array}{l}\text { Mean recovery } \\
\% \pm \mathrm{RSD} \%\end{array}$ & \\
\hline LLOQ & $94.61 \pm 8.53$ & $99.91 \pm 9.87$ & $105.35 \pm 4.51$ & $102.42 \pm 3.19$ \\
\hline QCL & $98.85 \pm 6.41$ & $97.95 \pm 7.26$ & $101.90 \pm 6.77$ & $100.98 \pm 7.47$ \\
\hline QCM & $99.71 \pm 3.93$ & $103.02 \pm 6.52$ & $107.21 \pm 3.24$ & $105.02 \pm 4.15$ \\
\hline $\mathrm{OCH}$ & $106.16 \pm 2.72$ & $104.86 \pm 2.09$ & $94.71 \pm 2.57$ & $100.68 \pm 3.11$ \\
\hline
\end{tabular}

Table 5 Recovery and process efficiency for the determination of LEV by HPLC assay

\begin{tabular}{|c|c|c|c|}
\hline & \multirow{2}{*}{$\begin{array}{l}\text { Recovery } \\
\text { Mean RE\% } \\
\pm \text { RSD\% }\end{array}$} & \multicolumn{2}{|l|}{ Process efficiency } \\
\hline & & $\begin{array}{l}\text { Mean } \mathrm{PE} \% \pm \mathrm{RSD} \% \\
\text { (after protein ppt.) }\end{array}$ & $\begin{array}{l}\text { Mean PE\% } \pm \text { RSD\% } \\
\text { (after MI-MSPE) }\end{array}$ \\
\hline QCL & $92.02 \pm 5.51$ & - & $91.88 \pm 4.15$ \\
\hline QCM & $91.52 \pm 6.52$ & $90.22 \pm 4.59$ & $89.44 \pm 2.26$ \\
\hline \multirow[t]{2}{*}{$\mathrm{QCH}$} & $93.88 \pm 6.62$ & - & $89.17 \pm 1.08$ \\
\hline & $n=6$ & $n=6$ & $n=6$ \\
\hline
\end{tabular}

for plasma samples (blank and spiked) are shown in Fig. S6 and $\mathrm{S} 7 \dagger$ respectively. These results demonstrated the high selectivity of the method as it allowed cleaner extracts to be obtained with no interference from endogenous components of biological matrices.

II. Linearity and lower limit of quantitation. The average of six determinations at six concentration levels covering the range of $10-80 \mu \mathrm{g} \mathrm{mL}^{-1}$ for LEV was used to estimate the linearity. The mean values for the regression equations were (AUC = 1.2283conc $+20.753, r=0.9993)$ and (Abs $=0.0091$ conc + $0.3031, r=0.9994)$ for HPLC and colorimetric assay respectively. Blank samples were used to confirm the absence of interference and reproducibility of sample preparation. The LOD and the LOQ values of LEV were $2.58 \mathrm{~g} \mathrm{~mL}^{-1}$ and $7.81 \mathrm{~g}$ $\mathrm{mL}^{-1}$, respectively for HPLC assay and $2.32 \mathrm{~g} \mathrm{~mL}^{-1}$ and $7.02 \mathrm{~g}$ $\mathrm{mL}^{-1}$, respectively for colorimetric assay.

III. Accuracy and precision. Analysis of spiked plasma samples at LLOQ, QCL, QCM, and QCH revealed that the within-run accuracy was 94.61-106.16\% and 94.71-105.35\% with a precision of $2.72-8.53 \%$ and $2.57-6.77 \%$ for HPLC and colorimetric assay respectively (Table 4). The between-run accuracy was within $97.95-104.86 \%$ and $100.68-105.02 \%$ with RSD of $2.09-9.87 \%$ and $3.11-7.47 \%$ for HPLC and colorimetric assay respectively (Table 4). Obtained results indicated that both assays possess acceptable accuracy and precision.

IV. Recovery and process efficiency. MI-MSPE using $\mathrm{Fe}_{3} \mathrm{O}_{4}$ @MIP NPs was found to be a suitable approach to achieve reliable recovery of $\mathrm{LEV}$ in plasma samples. The recoveries were measured at the QC levels in six replicates. Results demonstrated that the mean percentage recovery of LEV was in the range of 91.52-93.88\% and 91.74-93.47\% with RSD of 5.51-62\% and $1.44-8.14 \%$, as summarized in Tables 5 and 6 for HPLC and

Table 6 Recovery and process efficiency for the determination of LEV by colorimetric assay

\begin{tabular}{llll}
\hline & Recovery & & Process efficiency \\
\cline { 2 - 2 } $\begin{array}{lll}\text { Mean RE\% } \\
\pm \text { RSD\% }\end{array}$ & & $\begin{array}{l}\text { Mean PE\% } \pm \\
\text { RSD\% (after MI-MSPE) }\end{array}$ \\
\hline QCL & $93.47 \pm 1.44$ & $89.31 \pm 8.35$ \\
QCM & $92.91 \pm 3.29$ & $90.59 \pm 4.39$ \\
QCH & $91.74 \pm 8.14$ & $89.17 \pm 2.58$ \\
& $n=6$ & $n=6$
\end{tabular}


colorimetric assays respectively. The process efficiency was evaluated in the studied QC plasma samples and the mean peak areas or absorbances of LEV were compared to those obtained from analysis of neat standards of equivalent concentrations. The results of process efficiency for the two proposed assays are demonstrated in Tables 5 and 6 respectively. The mean percentage recovery of LEV was in the range of $89.17-91.88 \%$ and $89.17-90.59 \%$ and with RSD of $1.08-4.15 \%$ and $2.58-8.35 \%$, for the HPLC and colorimetric assays respectively. In addition, the recovery of LEV after extraction via protein precipitation (90.22\%) was almost similar to that after MI-MSPE (89.44\%) which gives an indication that there was almost no loss of LEV after the 2-step extraction technique, yet a purer extract was obtained (Fig. S6[e] and [f] $\dagger$ ).

\section{Conclusions}

In the present work, fully optimized and validated MI-MSPE/ HPLC-UV and MIMSPE/colorimetric methods for extraction and determination of the anti-epileptic drug; levetiracetam in human plasma samples was presented. $\mathrm{Fe}_{3} \mathrm{O}_{4} @$ MIP NPs were synthesized with a molecularly imprinted polymer layer on $\mathrm{Fe}_{3} \mathrm{O}_{4}$ NPs by surface imprinting and nano techniques. Results indicated the successfulness of using the computer-aided design for the rational selection of functional monomers and solvents to improve the properties of the fabricated MIP. Our $\mathrm{Fe}_{3} \mathrm{O}_{4} @$ MIP NPs just needed $30 \mathrm{~min}$ to reach the adsorption equilibrium with a maximum adsorption capacity of $26.04 \mathrm{mg}$ $\mathrm{g}^{-1}$. Moreover, the successful selective separation and enrichment of LEV in human plasma samples designate that the $\mathrm{Fe}_{3} \mathrm{O}_{4} @$ MIP NPs has a unique extraction ability where the extract is almost free of any foreign bodies other than the desired template. Thus, the combination of the proposed sample preparation technique with simple analytical assays e.g.: spectrophotometry, can provide a fast, reliable, cost-effective approach for analysis of various types of chemical compounds in different kinds of matrices.

\section{Conflicts of interest}

There are no conflicts to declare.

\section{Acknowledgements}

We thank Dr Ahmed Refaat Gardouh from Pharmaceutics and Industrial pharmacy department, Faculty of Pharmacy, Suez Canal University, Egypt for his guidance in the synthesis of MIP NPs.

\section{References}

1 C. Bylda, R. Thiele, U. Kobold and D. A. Volmer, Analyst, 2014, 139, 2265.

2 S. Azodi-Deilami, M. Abdouss, E. Asadi, A. Hassani Najafabadi, S. Sadeghi, S. Farzaneh and S. Asadi, J. Appl. Polym. Sci., 2014, 131, 41209.
3 J. L. Benedé, A. Chisvert, D. L. Giokas and A. Salvador, Anal. Chim. Acta, 2016, 926, 63-71.

4 P. Lucci, D. Derrien, F. Alix, C. Pérollier and S. Bayoudh, Anal. Chim. Acta, 2010, 672, 15-19.

5 X. Su, X. Li, J. Li, M. Liu, F. Lei, X. Tan, P. Li and W. Luo, Food Chem., 2015, 171, 292-297.

6 S. Azodi-Deilami, M. Abdouss and S. Hasani, Open Chem., 2010, 8, 861-869.

7 E. Asadi, S. Azodi-Deilami, M. Abdouss, D. Kordestani, A. Rahimi and S. Asadi, Korean J. Chem. Eng., 2014, 31, 1028-1035.

8 S. Azodi-Deilami, M. Abdouss and D. Kordestani, Appl. Biochem. Biotechnol., 2014, 172, 3271-3286.

9 X. Wang, L. Wang, X. He, Y. Zhang and L. Chen, Talanta, 2009, 78, 327-332.

10 A.-H. Lu, E. L. Salabas and F. Schüth, Angew. Chem., Int. Ed., 2007, 46, 1222-1244.

11 Y.-L. Zhang, J. Zhang, C.-M. Dai, X.-F. Zhou and S.-G. Liu, Carbohydr. Polym., 2013, 97, 809-816.

12 M. Díaz-Álvarez, E. Turiel and A. Martín-Esteban, J. Chromatogr. A, 2016, 1469, 1-7.

13 X. Kong, R. Gao, X. He, L. Chen and Y. Zhang, J. Chromatogr. A, 2012, 1245, 8-16.

14 G. Sheykhaghaei, M. H. Sadr and S. Khanahmadzadeh, Bull. Mater. Sci., 2016, 39, 647-653.

15 R. Gao, X. Mu, Y. Hao, L. Zhang, J. Zhang and Y. Tang, J. Mater. Chem. B, 2014, 2, 1733-1741.

16 R. Gao, Y. Hao, L. Zhang, X. Cui, D. Liu, M. Zhang, Y. Tang and Y. Zheng, Chem. Eng. J., 2016, 284, 139-148.

17 Y. Su, B. Qiu, C. Chang, X. Li, M. Zhang, B. Zhou and Y. Yang, RSC Adv., 2018, 8, 6192-6199.

18 R. Gao, X. Cui, Y. Hao, L. Zhang, D. Liu and Y. Tang, Food Chem., 2016, 194, 1040-1047.

19 J. Martens-Lobenhoffer and S. M. Bode-Böger, J. Chromatogr. B: Anal. Technol. Biomed. Life Sci., 2005, 819, 197-200.

20 F. M. C. Besag and D. Berry, Drug Saf., 2006, 29, 95-118.

21 J. J. Luszczki, M. M. Andres, P. Czuczwar, A. CioczekCzuczwar, J. Wojcik-Cwikla, N. Ratnaraj, P. N. Patsalos and S. J. Czuczwar, Eur. Neuropsychopharmacol., 2005, 15, 609616.

22 H. R. Adams, J. E. Riviere and M. G. Papich, Veterinary Pharmacology and Therapeutics., Wiley, 2013.

23 V. P. Shah, K. K. Midha, J. W. Findlay, H. M. Hill, J. D. Hulse, I. J. McGilveray, G. McKay, K. J. Miller, R. N. Patnaik, M. L. Powell, A. Tonelli, C. T. Viswanathan and A. Yacobi, Pharm. Res., 2000, 17, 1551-1557.

24 E. A. Wilson and M. J. Brodie, Baillieres Clin. Neurol., 1996, 5, 723-747.

25 E. Perucca and M. Bialer, Clin. Pharmacokinet., 1996, 31, 2946.

26 J. M. Pellock, T. A. Glauser, E. M. Bebin, N. B. Fountain, F. J. Ritter, R. M. Coupez and W. D. Shields, Epilepsia, 2001, 42, 1574-1579.

27 T. A. Vermeij and P. M. Edelbroek, J. Chromatogr. B: Biomed. Sci. Appl., 1994, 662, 134-139.

28 V. Pucci, F. Bugamelli, R. Mandrioli, A. Ferranti, E. Kenndler and M. A. Raggi, Biomed. Chromatogr., 2004, 18, 37-44. 
29 T. A. Glauser, W. G. Mitchell, A. Weinstock, M. Bebin, D. Chen, R. Coupez, A. Stockis and Z. Lu, Epilepsia, 2007, 48, 1117-1122.

30 L. Wang and Z. Zhang, Talanta, 2008, 76, 768-771.

31 Molecular Operating Environment (MOE), 2012, Chemical Computing Group Inc., 1010 Sherbrooke St. West, Suite \#910, Montreal, QC, Canada, H3A 2R7.

32 M. J. Frisch, G. W. Trucks, H. B. Schlegel, G. E. Scuseria, et al., (2009), Gaussian 09 Revision D.01, Gaussian Inc., Wallingford.

33 M. Cossi, V. Barone and R. Cammi, Chem. Phys. Lett., 1996, 255, 327-335.

34 W. Humphrey and A. Dalke, J. Mol. Graphics, 1996, 14, 33-38. 35 M. Tabandeh, S. Ghassamipour, H. Aqababa and M. Tabatabaei, J. Chromatogr. B: Anal. Technol. Biomed. Life Sci., 2012, 898, 24-31.

36 N. T. Abdel Ghani, R. M. El Nashar and F. M. Abdel-Haleem, Electroanalysis, 2016, 28, 1530-1538.

37 J. L. Benedé, A. Chisvert, D. L. Giokas and A. Salvador, J. Chromatogr. A, 2014, 1362, 25-33.

38 I. Guideline, Q2A Text on Validation of Analytical Procedures, Fed. Regist. (1994), http://www.hc-sc.gc.ca/dhpmps/prodpharma/applic-demande/guide-ld/ich/qual/q2aeng.php, accessed February 28, 2018.

39 I. Guideline, Validation of analytical procedures: Text and Methodology, Q2. (2005), http://somatek.com/content/ uploads/2014/06/sk140605h.pdf, February 28, 2018.

40 International Conference on Harmonization (ICH), Q2B, Validation of Analytical Procedures: Definitions and Terminology, vol. 60, US FDA Federal Register, 1995.

41 O. A. Attallah, M. A. Al-Ghobashy, M. Nebsen and M. Y. Salem, RSC Adv., 2016, 6, 11461-11480.

42 D. K. Yi, S. S. Lee, G. C. Papaefthymiou and J. Y. Ying, Chem. Mater., 2006, 18, 614-619.
43 L. Chen, Y. Liu, X. He and Y. Zhang, Chin. J. Chromatogr., 2015, 33, 481-487.

44 M. Safdarian, Z. Ramezani and A. A. Ghadiri, J. Chromatogr. A, 2016, 1455, 28-36.

45 M. Indupriya, R. S. Chandan, B. M. Gurupadayya and K. Sowjanya, Der Pharma Chemica, 2011, 3, 472-481.

46 M. Abdouss, S. Azodi-Deilami, E. Asadi and Z. Shariatinia, J. Mater. Sci. Mater. Med., 2012, 23, 1543-1552.

47 I. Langmuir, J. Am. Chem. Soc., 1918, 40, 1361-1403.

$48 \mathrm{H}$. Freundlich, Über die Adsorption in Lösungen, W. Engelmann, 1906.

49 R. Sips, J. Chem. Phys., 1948, 16, 490.

50 A. Z. M. Badruddoza, G. S. S. Hazel, K. Hidajat and M. S. Uddin, Colloids Surf., A, 2010, 367, 85-95.

$51 \mathrm{~S}$. Lagergren, About the theory of so-called adsorption of soluble substances, K. Sven. Vetenskapsakad. Handl., 1898, 24, 1-39.

52 Y. Ho and G. McKay, Process Biochem., 1999, 34, 451-465.

53 D.-M. Han, G.-Z. Fang and X.-P. Yan, J. Chromatogr. A, 2005, 1100, 131-136.

54 M. Lasáková, D. Thiébaut, P. Jandera and V. Pichon, J. Sep. Sci., 2009, 32, 1036-1042.

55 M. A. A. El-Aal, M. A. Al-Ghobashy, F. A. A. Fathalla and Y. S. El-Saharty, J. Chromatogr. B: Anal. Technol. Biomed. Life Sci., 2017, 1046, 34-47.

56 R. J. Flanagan and Wiley InterScience (Online service), Fundamentals of analytical toxicology, John Wiley \& Sons, 2007.

57 C. Dong, Y. Zhang, L. Guo and Q. Li, J. Anal. Chem., 2010, 65, 707-712.

58 H. C. Yao, E. J. Xu, W. Y. Zeng, X. Y. Zeng, M. Zhang and J. Chen, J. Food Drug Anal., 2013, 21, 279-285. 